\title{
Therapeutic approach of uterine leiomyoma; choosing the most appropriate surgical option
}

\author{
Anca Daniela Stanescu ${ }^{1,2}$, Mihai George Loghin ${ }^{2}$, Liana Ples ${ }^{1,2}$, Daniela Gabriela Balan ${ }^{1}$, \\ Ioana Paunica ${ }^{1}$, Oana Denisa Balalau ${ }^{1,2 *}$ \\ ${ }^{1}$ CAROL DAVILA UNIVERSITY OF MEDICINE AND PHARMACY, BUCHAREST, ROMANIA \\ ${ }^{2}$ BUCUR MATERNITY, ST. JOHN CLINICAL EMERGENCY HOSPITAL, DEPARTMENT OF OBSTETRICS AND GYNECOLOGY, BUCHAREST, ROMANIA
}

\begin{abstract}
The most common benign pelvic tumor in young women is uterine leiomyoma. It is often asymptomatic, but can cause symptoms such as pelvic-abdominal pain, vaginal bleeding, urinary and intestinal transit disorders. If there is a suspicion of malignancy, it is necessary to perform fractional uterine curettage to establish the histopathological diagnosis. The surgical treatment of uterine leiomyoma includes several procedures: myomectomy, subtotal or total hysterectomy. The procedure will be chosen depending on the patient's particularities: BMI, uterine size, leiomyoma location, surgical history or other associated pathologies. Laparoscopic hysterectomy has a 45-minute shorter duration of intervention than vaginal hysterectomy, and the conversion rate to the open procedure is lower. Laparoscopically treated cases have fewer postoperative complications compared to other surgical procedures and have a shorter hospitalization and recovery time. The recurrence rate of uterine leiomyoma is similar for both laparoscopic and open abdominal approach, and the frequency of long-term complications such as adhesion syndrome or pelvic pain is higher after the latter.
\end{abstract}

\author{
Category: Review \\ Received: September 05, 2020 \\ Accepted: November 12, 2020 \\ Published: May 10, 2021 \\ Keywords: \\ uterine, leiomyoma, surgery, hysterectomy, myomectomy \\ * Corresponding author: \\ Oana Denisa Balalau, \\ Carol Davila University of Medicine and Pharmacy, Department \\ of Obstetrics and Gynecology, St. John Clinical Emergency \\ Hospital, Bucharest, Romania 040292 \\ E-mail: doctor.balalau@gmail.com
}

\section{Introduction}

Uterine leiomyoma is the most common benign pelvic tumor in women of young age [1,2]. The tissue that represents the origin of tumor proliferation is smooth muscle fiber [3]. In most cases, uterine fibroids are asymptomatic and can develop for a long time until they are diagnosed [4-6]. In terms of signs and symptoms they most commonly produce pelvic-abdominal pain, vaginal bleeding, urinary disorders and intestinal transit disorders because of their volume [7-10]. These clinical manifestations suggest the need for surgical treatment for benign uterine tumors. When there is a suspicion of malignancy due to the presence of risk factors or by imaging signs detected preoperatively, it is necessary to perform a fractionated biopsy uterine curettage with histopathological evaluation. Depending on this, the benignity or malignancy of the tumor will be decided and the appropriate type of operation will be chosen [11].

Surgical treatment of uterine leiomyoma includes several procedures: laparoscopic, abdominal, vaginal or hysteroscopic myomectomy, subtotal hysterectomy performed laparoscopically or abdominally, total hysterectomy (TH) that can be performed through different approach: vaginal, abdominal, laparoscopic [12,13]. TH with bilateral salpingo-oophorectomy was the reference intervention for patients older than 45 years. Recently, a new technique has been adopted: TH with bilateral salpingectomy, because it is considered that ovarian epithelial tumors have as a starting point the fallopian tube epithelium [49].

The approach will be chosen depending on the patient's particularities: BMI, uterine size, leiomyoma location, surgical history or other associated pathologies. It should be noted that the Trendelenburg position and peritoneal insufflation with carbon dioxide may be contraindicated in certain situations [14].

Another method of surgical treatment of uterine leiomyoma is myomectomy. As in the case of total hysterectomy, this intervention can be performed by multiple approaches: laparoscopic, abdominal, vaginal and hysteroscopic. Laparoscopic myomectomy presents 
increased risks when the tumor is larger than $5 \mathrm{~cm}$, requires the removal of more than 3 tumors or if the location is intraligamentary or intramural, due to the increased risk of bleeding [26]. Hysteroscopic myomectomy is used for submucosal tumors. Among the absolute contraindications of the technique are acute or chronic acute infections of the female genital tract, malignant tumor pathology and intracavitary pregnancy [27]. Due to the saline infusion of the uterine cavity, the procedure should be performed carefully in patients with ischemic heart disease and cardiomyopathies [27]. Vaginal hysterectomy is indicated for cases with a normal, mobile volume uterus and a good vaginal approach [28].

\section{Discussions}

An analysis conducted in 2015 by Aarts \& al compared different types of approach in total hysterectomy, taking information from 47 studies that included 5102 cases. It was observed that the patients in whom the vaginal hysterectomy was chosen had a faster postoperative recovery by approximately 9.5 days, compared to the group of patients in whom the abdominal hysterectomy was chosen. In patients with laparoscopic hysterectomy, postoperative recovery was 13 days faster compared to the abdominal approach [29]. Regardless of the approach of total hysterectomy chosen, the quality of long-term life was identical between the two groups [29].

Compared to abdominal hysterectomy, vaginal hysterectomy has the advantages of a shorter hospitalization by one day, a lower risk of postoperative infections and a lower risk of bleeding [30,35]. A disadvantage of vaginal hysterectomy is the increased incidence of reoperations for postoperative hemorrhage [35]. In the case of laparoscopic hysterectomy, the hospitalization time was two days shorter than the patients who had an open approach, lower intraoperative bleeding and reduced risk of infection. The disadvantages of the laparoscopic approach are represented by the longer operating time by 20-27 minutes and the frequency of approx. 2.5 times the risk of urinary tract injuries, especially ureteral injuries [30].

Sandberg \& al performed a meta-analysis in which they compared vaginal hysterectomy with laparoscopic hysterectomy. It has been observed that the duration of surgery is reduced in the case of vaginal hysterectomy by 45 minutes and the conversion rate to the open procedure is lower [31,37]. Vaginal $\mathrm{TH}$ has the lowest risk of dehiscence of the vaginal cuff, while laparoscopic hysterectomy has a higher rate $(0.75 \%)$. The main disadvantage of the vaginal approach is due to the more intense pain syndrome during the early postoperative period [31,32]. A retrospective study conducted by Sailofsky S. showed that the most common urinary tract injury in vaginal hysterectomy is bladder injuries [37]. The rest of the postoperative risks and complications are similar to those of other approaches [31]. If we talk about the costefficiency relationship, vaginal hysterectomy is the method of choice, not only because of the short hospitalization time, but also because of the low rate of postoperative complications and the materials used during surgery [33, 34]. Vaginal hysterectomy has the lowest risk of bladder and ureteral injuries [36].

In the case of vaginal hysterectomy, the presence of a large tumor mass, malignancy or associated with severe adhesion syndrome are relative contraindications to the procedure. There are situations when vaginal hysterectomy is considered difficult: nulliparous, obese patients, history of pelvic radiotherapy and pelvic surgery, including cesarean delivery. None of the above situations is an absolute contraindication to vaginal hysterectomy [15-17].

If the chosen approach is the laparoscopic one, the surgery can be done completely laparoscopically or by combining the laparoscopic technique with the vaginal one [18-20]. For this approach a BMI over $30 \mathrm{~kg} / \mathrm{m} 2$ is not a contraindication, but in this condition, it was observed that the operating time is increased, and the situations that require conversion to total abdominal hysterectomy are common [21-24]. The abdominal approach has two types of hysterectomy: extrafascial, the most often used and intrafascial [25]. The second technique preserves the pubovesico-cervical fascia, thus keeping intact the vascularnervous complex of the cervico-vaginal junction [25]. If an intrafasial technique is desired, excessive penetration into the cervical muscle tissue should be avoided during dissection due to the increased risk of bleeding [25].

Following a three-year retrospective study conducted in 2002 by Beuassi \& al. that analyzed total abdominal hysterectomy compared to total vaginal hysterectomy for large uterine tumors, it was observed that the intervention time was shorter by 16 minutes for vaginal hysterectomy. Intraoperative and postoperative hemorrhagic complications had a similar prevalence between the two approaches. Infectious and pain complications are more common in the open surgical approach. For the vaginal approach of the uteri of enlarged uterus, the morcellation is used. The study concluded that vaginal hysterectomy has definite benefits even in large uterine leiomyomas [38].

In 2014, the Food and Drug Administration (FDA) raised the issue of intrabdominal and intraperitoneal dissemination of benign and malignant uterine tumors following morcellation [39]. There are cases in the literature that describe the morcellation of a uterine tumor considered benign, both preoperatively (imaging, clinical) and intraoperatively which has been confirmed as leiomyosarcoma at the histopathology exam [40]. The study led by Bogani $G$ analyzed the cases in which the diagnosis of malignancy was made after histopathological examination, after the uterus had been morcellated [40]. 
The risk of recurrence is higher in the case of morcellation (62\% compared to $39 \%$ ), the risk of intrabdominal dissemination of tumor cells being approximately 4.3 times higher, and the medium-term survival reduced by half [40]. For stage I leiomyosarcoma, the only difference between morcellating the piece and removing it as a whole was the rate of survival at one-year [41].

The study by George $\mathrm{S} \&$ al. concluded that the prevalence of leiomyosarcoma is $0.1-0.2 \%$ of the total hysterectomies in which the morcellator was used [42]. Intraoperative fragmentation increases the possibility of intrapelvic dissemination of the tumor, increases the risk of recurrence and shortens the time of its occurrence 11 months in the case of tumor fragmentation and 40 months in its absence) [42].

Another problem with uterine tumor morcellation is localized or diffuse intraperitoneal leiomyomatosis [43]. The most common locations of these nodules are large and small intestine, pelvic wall, right abdominal muscles [43]. The study led by Lu B \& al. identified only one case of diffuse peritoneal leiomyomatosis [43].

According to the latest FDA indications, laparoscopy with tumor fragmentation is contraindicated in perimenopause and postmenopause, and the patient must be informed about the risk of malignant tumor cells in the uterine tumor, with decreased long-term life expectancy [44].

Subtotal hysterectomy is the surgical procedure by which the uterine body and preserved cervix are removed. Subtotal hysterectomy does not bring benefits compared to total hysterectomy in terms of sexual quality of life, urinary and intestinal manifestations and long-term risk of genital prolapse $[45,46]$. The duration of the operation for subtotal hysterectomy is 11 minutes shorter than for the total one and the risk of bleeding is low, but they do not bring considerable benefits [45].

Wei et al. analyzed the conservative treatment of uterine leiomyoma: vaginal and abdominal myomectomy. There were no differences in terms of operative time, intraoperative hemorrhage, number of excised tumors, tumor weight or early postoperative course, except for body temperatures which is elevated in vaginal myomectomy [47]. The indications for myomectomy are uterine size smaller than a 16-week pregnancy, lack of severe adherent syndrome or ovarian pathology [47]. According to Jin \& al. the overall risk of postoperative complications was lower for laparoscopically treated cases, but there are insufficient statistical data for major complications such as pulmonary thromboembolism or massive hemorrhage that need of volume replacement [48]. The recurrence rate is similar between the laparoscopic and abdominal approaches [49]. The definite advantage of laparoscopy is the decrease in the frequency of adhesion syndrome and pain syndrome [49].

\section{Conclusions}

Total vaginal hysterectomy is the method of choice in the treatment of uterine leiomyomatosis due to early postoperative recovery and lower associated risks compared to the other approaches.

Due to the risk of peritoneal leiomyomatosis and dissemination of cancerous cells in the peritoneum, morcellation of uterine tumors is not recommended.

Subtotal hysterectomy does not bring additional benefits to total hysterectomy in terms of quality of life, risk of genital prolapse and sex life.

Laparoscopic hysterectomy should be performed in the center with experience, because the risk of dehiscence of vaginal cuff and ureteral lesions.

\section{Conflict of interest disclosure}

There are no known conflicts of interest in the publication of this article. The manuscript was read and approved by all authors.

\section{Compliance with ethical standards}

Any aspect of the work covered in this manuscript has been conducted with the ethical approval of all relevant bodies and that such approvals are acknowledged within the manuscript.

\section{References}

1. Baird DD, Dunson DB, Hill MC, Cousins D, Schectman JM. High cumulative incidence of uterine leiomyoma in black and white women: ultrasound evidence. Am J Obstet Gynecol. 2003;188(1):100-7. doi: 10.1067/mob.2003.99

2. Serden SP, Brooks PG. Treatment of abnormal uterine bleeding with the gynecologic resectoscope. J Reprod Med. 1991;36(10):697-9.

3. Stewart EA, Cookson CL, Gandolfo RA, Schulze-Rath R. Epidemiology of uterine fibroids: a systematic review. BJOG. 2017;124(10):1501-1512. doi: 10.1111/1471-0528.14640

4. Ghant MS, Sengoba KS, Recht H, Cameron KA, Lawson AK, Marsh EE. Beyond the physical: a qualitative assessment of the burden of symptomatic uterine fibroids on women's emotional and psychosocial health. J Psychosom Res. 2015;78(5):499-503. doi: 10.1016/j.jpsychores.2014.12.016

5. Ghant MS, Sengoba KS, Vogelzang R, Lawson AK, Marsh EE. An Altered Perception of Normal: Understanding Causes for Treatment Delay in Women with Symptomatic Uterine Fibroids. J Womens Health (Larchmt). 2016; 25(8):846-52. doi: 10.1089/jwh.2015.5531

6. Borah BJ, Nicholson WK, Bradley L, Stewart EA. The impact of uterine leiomyomas: a national survey of affected 
women. Am J Obstet Gynecol. 2013;209(4):319.e1319.e20. doi: 10.1016/j.ajog.2013.07.017

7. Stewart EA. Clinical practice. Uterine fibroids. $N$ Engl J Med. 2015;372(17):1646-55. doi: 10.1056/NEJMcp 1411029

8. Stewart EA, Nicholson WK, Bradley L, Borah BJ. The burden of uterine fibroids for African-American women: results of a national survey. $J$ Womens Health (Larchmt). 2013;22(10):807-16. doi: 10.1089/jwh.2013.4334

9. Fraser IS, Critchley HO, Munro MG, Broder M; Writing Group for this Menstrual Agreement Process. A process designed to lead to international agreement on terminologies and definitions used to describe abnormalities of menstrual bleeding. Fertil Steril. 2007;87(3):466-76. doi: 10.1016/j.fertnstert.2007.01.023

10. Committee on Practice Bulletins-Gynecology. Practice bulletin no. 128: diagnosis of abnormal uterine bleeding in reproductive-aged women. Obstet Gynecol. 2012;120(1):197-206. doi: 10.1097/AOG.0b013e318262e320

11. Murphy KM, Carrick K, Gwin K, Rogers V, Koduru P, Ronnett BM, Castrillon DH. Rare Complete Hydatidiform Mole With p57 Expression in Villous Mesenchyme: Case Report and Review of Discordant p57 Expression in Hydatidiform Moles. Int J Gynecol Pathol. 2021; doi: 10.1097/PGP.0000000000000773

12. Garry R, Fountain J, Mason S, Hawe J, Napp V, Abbott J, Clayton R, Phillips G, Whittaker M, Lilford R, Bridgman S, Brown J. The eVALuate study: two parallel randomised trials, one comparing laparoscopic with abdominal hysterectomy, the other comparing laparoscopic with vaginal hysterectomy. BMJ. 2004;328(7432):129. doi: 10.1136/bmj.37984.623889.F6

13. Radosa JC, Meyberg-Solomayer G, Kastl C, Radosa CG, Mavrova R, Gräber S, Baum S, Radosa MP. Influences of different hysterectomy techniques on patients' postoperative sexual function and quality of life. J Sex Med. 2014;11(9):2342-50. doi: $10.1111 /$ jsm. 12623

14. Kim S, Brooks AK, Groban L. Preoperative assessment of the older surgical patient: honing in on geriatric syndromes. Clin Interv Aging. 2014;10:13-27. doi: 10.2147/CIA.S75285

15. Nulens K, Kempenaers R, Baekelandt J. Hysterectomy via vaginal Natural Orifice Transluminal Endoscopic Surgery in virgin patients: a first feasibility study. J Obstet Gynaecol. 2021;23:16. doi: 10.1080/01443615.2020.1867972

16. Doucette RC, Sharp HT, Alder SC. Challenging generally accepted contraindications to vaginal hysterectomy. Am J Obstet Gynecol. 2001; 184(7):1386-9. doi: 10.1067/mob.2001.115047

17. Hesselman S, Högberg U, Jonsson M. Effect of remote cesarean delivery on complications during hysterectomy: a cohort study. Am J Obstet Gynecol. 2017;217(5):564.e1564.e8. doi: 10.1016/j.ajog.2017.07.021

18. Olive DL, Parker WH, Cooper JM, Levine RL. The AAGL classification system for laparoscopic hysterectomy. Classification committee of the American Association of Gynecologic Laparoscopists. J Am Assoc Gynecol Laparosc. 2000;7(1):9-15. doi: 10.1016/s1074-3804(00)80004-3

19. Nezhat C, Nezhat F, Admon D, Nezhat AA. Proposed classification of hysterectomies involving laparoscopy. J Am Assoc Gynecol Laparosc. 1995;2(4):427-9. doi: 10.1016/s1074-3804(05)80065-9

20. Richardson RE, Bournas N, Magos AL. Is laparoscopic hysterectomy a waste of time? Lancet. 1995;345(8941):36-41. doi: 10.1016/s01406736(95)91158-8

21. Chopin N, Malaret JM, Lafay-Pillet MC, Fotso A, Foulot H, Chapron C. Total laparoscopic hysterectomy for benign uterine pathologies: obesity does not increase the risk of complications. Hum Reprod. 2009;24(12):3057-62. doi: 10.1093/humrep/dep348

22. McMahon MD, Scott DM, Saks E, Tower A, Raker CA, Matteson KA. Impact of obesity on outcomes of hysterectomy. J Minim Invasive Gynecol. 2014; 21(2):259-65. doi: 10.1016/j.jmig.2013.08.707

23. Camanni M, Bonino L, Delpiano EM, Migliaretti G, Berchialla P, Deltetto F. Laparoscopy and body mass index: feasibility and outcome in obese patients treated for gynecologic diseases. J Minim Invasive Gynecol. 2010;17(5):576-82. doi: 10.1016/j.jmig.2010.04.002

24. Driessen SR, Sandberg EM, la Chapelle CF, Twijnstra AR, Rhemrev JP, Jansen FW. Case-Mix Variables and Predictors for Outcomes of Laparoscopic Hysterectomy: A Systematic Review. J Minim Invasive Gynecol. 2016;23(3):317-30. doi: 10.1016/j.jmig.2015.11.008

25. Kaya H, Sezik M, Ozbasar D, Ozkaya O, Sahiner H. Intrafascial versus extrafascial abdominal hysterectomy: effects on urinary urge incontinence. Int Urogynecol J Pelvic Floor Dysfunct. 2004;15(3):1714. doi: 10.1007/s00192-004-1136-x

26. Sizzi O, Rossetti A, Malzoni M, Minelli L, La Grotta F, Soranna L, Panunzi S, Spagnolo R, Imperato F, Landi S, Fiaccamento A, Stola E. Italian multicenter study on complications of laparoscopic myomectomy. J Minim Invasive Gynecol. 2007;14(4):453-62. doi: 10.1016/j.jmig.2007.01.013

27. Abuzeid O, Ibrahim M, Joseph S, Herbert J, Abuzeid M. Safety and efficacy of hysteroscopic resection of uterine leiomyoma embedded at the base of a uterine septum. Facts Views Vis Obgyn. 2021;12(4):273-280.

28. Plotti G, Plotti F, Di Giovanni A, Battaglia F, Nagar G. Feasibility and safety of vaginal myomectomy: a prospective pilot study. J Minim Invasive Gynecol. 2008;15(2):166-71. doi: 10.1016/j.jmig.2007.09.010 
29. Aarts JW, Nieboer TE, Johnson N, Tavender E, Garry R, Mol BW, Kluivers KB. Surgical approach to hysterectomy for benign gynaecological disease. Cochrane Database Syst Rev. 2015;2015(8):CD003677. doi: 10.1002/14651858.CD003677.pub5

30. Nieboer TE, Johnson N, Lethaby A, Tavender E, Curr E, Garry R, van Voorst S, Mol BW, Kluivers KB. Surgical approach to hysterectomy for benign gynaecological disease. Cochrane Database Syst Rev. 2009 Jul 8;(3):CD003677. doi: 10.1002/14651858.CD003677.pub4

31. Sandberg EM, Twijnstra ARH, Driessen SRC, Jansen FW. Total Laparoscopic Hysterectomy Versus Vaginal Hysterectomy: A Systematic Review and MetaAnalysis. J Minim Invasive Gynecol. 2017;24(2):206217.e22. doi: 10.1016/j.jmig.2016.10.020

32. Hur HC, Donnellan N, Mansuria S, Barber RE, Guido $\mathrm{R}$, Lee T. Vaginal cuff dehiscence after different modes of hysterectomy. Obstet Gynecol. 2011;118(4):794801. doi: 10.1097/AOG.0b013e31822f1c92

33. Dorsey JH, Holtz PM, Griffiths RI, McGrath MM, Steinberg EP. Costs and charges associated with three alternative techniques of hysterectomy. $N$ Engl J Med. 1996;335(7):476-82. doi: 10.1056/NEJM199608153350705

34. Sculpher M, Manca A, Abbott J, Fountain J, Mason S, Garry R. Cost effectiveness analysis of laparoscopic hysterectomy compared with standard hysterectomy: results from a randomised trial. BMJ. 2004;328(7432):134. doi: 10.1136/bmj.37942.601331.EE

35. Spilsbury K, Hammond I, Bulsara M, Semmens JB. Morbidity outcomes of 78,577 hysterectomies for benign reasons over 23 years. BJOG. 2008;115(12):1473-83. doi: 10.1111/j.14710528.2008.01921.x. PMID: 19035986.

36. Teeluckdharry B, Gilmour D, Flowerdew G. Urinary Tract Injury at Benign Gynecologic Surgery and the Role of Cystoscopy: A Systematic Review and Metaanalysis. Obstet Gynecol. 2015;126(6):1161-1169. doi: 10.1097/AOG.0000000000001096

37. Sailofsky S, Darin C, Alfahmy A, Sheyn D. Comparison of Surgical Outcomes After Total Laparoscopic Hysterectomy or Total Vaginal Hysterectomy for Large Uteri. Obstet Gynecol. 2021;137(3):445-453. doi: 10.1097/AOG.0000000000004274

38. Benassi L, Rossi T, Kaihura CT, Ricci L, Bedocchi L, Galanti B, Vadora E. Abdominal or vaginal hysterectomy for enlarged uteri: a randomized clinical trial. Am J Obstet Gynecol. 2002;187(6):1561-5. doi: 10.1067/mob.2002.127596

39. Stentz NC, Cooney LG, Sammel M, Shah DK. Changes in Myomectomy Practice After the U.S. Food and Drug Administration Safety Communication on Power Morcellation. Obstet Gynecol. 2017;129(6):10071013. doi: 10.1097/AOG.0000000000002035
40. Bogani G, Cliby WA, Aletti GD. Impact of morcellation on survival outcomes of patients with unexpected uterine leiomyosarcoma: a systematic review and meta-analysis. Gynecol Oncol. 2015;137(1):167-72. doi: 10.1016/j.ygyno.2014.11.011

41. Raine-Bennett T, Tucker LY, Zaritsky E, Littell RD, Palen T, Neugebauer R, Axtell A, Schultze PM, Kronbach DW, Embry-Schubert J, Sundang A, Bischoff K, Compton-Phillips AL, Lentz SE. Occult Uterine Sarcoma and Leiomyosarcoma: Incidence of and Survival Associated With Morcellation. Obstet Gynecol. 2016;127(1):29-39. doi: 10.1097/AOG.0000000000001187

42. George S, Barysauskas C, Serrano C, Oduyebo T, Rauh-Hain JA, Del Carmen MG, Demetri GD, Muto MG. Retrospective cohort study evaluating the impact of intraperitoneal morcellation on outcomes of localized uterine leiomyosarcoma. Cancer. 2014;120(20):3154-8. doi: 10.1002/cncr.28844

43. Lu B, Xu J, Pan Z. Iatrogenic parasitic leiomyoma and leiomyomatosis peritonealis disseminata following uterine morcellation. J Obstet Gynaecol Res. 2016;42(8):990-9. doi: 10.1111/jog.13011

44. Pritts EA, Parker WH, Brown J, Olive DL. Outcome of occult uterine leiomyosarcoma after surgery for presumed uterine fibroids: a systematic review. $J$ Minim Invasive Gynecol. 2015;22(1):26-33. doi: 10.1016/j.jmig.2014.08.781

45. Lethaby A, Mukhopadhyay A, Naik R. Total versus subtotal hysterectomy for benign gynaecological conditions. Cochrane Database Syst Rev. 2012;(4): CD004993. doi: 10.1002/14651858.CD004993.pub3

46. Andersen LL, Alling Møller LM, Gimbel HM. Objective comparison of subtotal vs. total abdominal hysterectomy regarding pelvic organ prolapse and urinary incontinence: a randomized controlled trial with 14-year follow-up. Eur J Obstet Gynecol Reprod Biol. 2015;193:40-5. doi: 10.1016/j.ejogrb.2015.06.033

47. Zhang RC, Wu W, Zou Q, Zhao H. Comparison of clinical outcomes and postoperative quality of life after surgical treatment of type II submucous myoma via laparoscopy or hysteroscopy. J Int Med Res. 2019;47(9):4126-4133. doi: 10.1177/0300060519858027

48. Jin C, Hu Y, Chen XC, Zheng FY, Lin F, Zhou K, Chen FD, Gu HZ. Laparoscopic versus open myomectomy-a meta-analysis of randomized controlled trials. Eur $J$ Obstet Gynecol Reprod Biol. 2009;145(1):14-21. doi: 10.1016/j.ejogrb.2009.03.009

49. Morelli M, Venturella R, Mocciaro R, Di Cello A, Rania E, Lico D, D'Alessandro P, Zullo F. Prophylactic salpingectomy in premenopausal low-risk women for ovarian cancer: primum non nocere. Gynecol Oncol. 2013;129(3):448-51. doi: 10.1016/j.ygyno.2013.03.023 